\title{
Fifteen-minute consultation on
}

\section{problems in the healthy child: sleep}

\author{
Jessica R Turnbull, ${ }^{1}$ Michael Farquhar ${ }^{2}$
}

\begin{abstract}
${ }^{1}$ Sunshine House Children and Young People's Development Centre, Guy's and St Thomas' NHS Foundation Trust, Community Children's Services, London, UK

${ }^{2}$ Department of Children's Sleep Medicine, Evelina London Children's Hospital, Guy's and St Thomas' NHS Foundation Trust, London, UK
\end{abstract}

\section{Correspondence to}

Dr Jessica R Turnbull, Sunshine House Children and Young People's Development Centre, Guy's and St Thomas' NHS Foundation Trust, Community Children's Services, 27 Peckham Road, London SE5 8UH, UK; Jessica.turnbull@gstt.nhs.uk

Received 4 February 2016 Revised 21 March 2016 Accepted 22 March 2016 Published Online First 25 April 2016

\section{CrossMark}

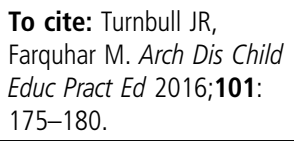

\section{ABSTRACT}

Sleep-related issues are common reasons children present to health professionals. Many factors can adversely affect sleep quality, and there are many associations of inadequate sleep, including behavioural problems, obesity and accidental injury. We review the current evidence, and suggest practical management strategies to promote better sleep, and hopefully, better functioning for child and family alike.

\section{INTRODUCTION}

Sleep is a vital function of life that we cannot survive without; it is therefore unsurprising that sleep-related presentations to healthcare professionals are common. ${ }^{1}$ Sleep-related issues are interesting, in that they may be a primary reason for seeking medical advice, but may also prove to be the underlying cause of other presenting problems. Additionally, many common health problems impact on sleep quality, including asthma, cough, gastro-oesophageal reflux, constipation, eczema, anxiety and seizures.

Poor sleep quality in children has been associated with hyperactivity, externalising behaviours, poor academic progress, symptoms of depression, daytime somnolence, bed-wetting, obesity and accidental injury. ${ }^{2-4}$ It is sometimes only by asking specifically that sleep issues are identified and appropriate management interventions suggested.

Behavioural sleep problems are common in otherwise well children, causing exhausted parents to seek answers as to why their child 'cannot sleep'- is something wrong?' and 'what can be done?' By the time parents reach a health professional, they will have sought advice from family, friends, and the internet. As health professionals, we must take parents' concerns seriously, and be in a position to answer their questions usefully (box 1).

\section{Case study}

A severely obese 15-year-old patient presented with enuresis, which resolved after treatment of her obstructive sleep apnoea; direct questioning about snoring allowed identification of the underlying issue. She was delighted that through non-invasive ventilation her enuresis was 'treated'.

\section{RANGE OF NORMALITY}

Parents may overestimate or underestimate the degree to which their child's sleep is disturbed. ${ }^{5}$ As objective monitoring is not always practical, it is important we acknowledge that we are managing parents' experience of their child's sleep as well as objectively identified problems.

So what is 'normal' when it comes to sleep patterns; when should health professionals be concerned, and when can parents be reassured?

\section{My child just doesn't sleep enough}

Sleep duration alters significantly over the life span, with average daily sleep duration ranging from $10-17 \mathrm{~h}$ at 6 months of age to $8-11 \mathrm{~h}$ at 11 years of age. ${ }^{6}$ If children are otherwise developmentally and physically well, they may be getting enough sleep for them; however potential adverse consequences of sleep deprivation should be considered before reassurance is given.

\section{My child just can't fall asleep}

There is a range of time taken to fall asleep (sleep onset latency), which averages $19 \mathrm{~min}$ for 0-2-year-olds, and 17 min for 3-12-year-olds. ${ }^{7}$ The level of tolerance parents may have for the time their child takes to fall asleep will differ, and the tactics children employ to maintain their parents' attention during this time will also differ ('I need a drink', 'I 


\section{Box 1 Targeted sleep history}

The first three questions provide a quick screen; if concerns are apparent more specific history can be gathered:

Does your child have any difficulty getting to sleep or staying asleep?

Does your child do anything unusual in the night?

Is your child unusually sleepy in the daytime?

When is bedtime?

What do you do in the hour leading up to bedtime?

How long does your child take to fall asleep after 'lights out'?

Where does your child fall asleep?

Does anybody need to be with the child while he/she is falling asleep?

Does your child sleep through, once asleep?

Does your child snore, have you noticed pauses in breathing when asleep?

Is your child restless in sleep?

What time does your child wake in the morning?

Is your child tired in the daytime? Does he/she fall asleep during activities?

What effect is this having on your family?

need a wee', 'just one more story', 'I don't like that shadow'). Limit setting is important, although if sleep onset is significantly delayed (beyond 30-45 min) further evaluation and intervention is warranted.

\section{The child wakes up all night}

Night wakenings are a normal part of the sleep cycle (figure 1); many children rouse and fall asleep again without conscious realisation up to four to five times a night, and without disturbing their parents. Night wakenings form a vital function during early infancy for feeding. As this need declines over the 1 st year, the habit of night-time feeding also needs to fall away. Children need to learn to settle by themselves if they wake; it is often the response to night-wakening that is important, rather than the wakening itself.

Sleep problems affect up to $25 \%$ of typically developing school-aged children, and up to $80 \%$ of children with neurodevelopmental disorders, ${ }^{i}$ however parents do not always seek advice, ${ }^{1}$ possibly due to 'normalising' the sleep disturbance, or with other priorities

\footnotetext{
'The exploration of sleep difficulties within neurodevelopmental disorders is beyond the scope of this article, however in basic terms, the range of what is 'normal' for sleep pattern within this group is very extensive, with some children with autism and other neurodevelopmental disorders, particularly Smith-Magenis syndrome, seemingly needing very little sleep. Basic principles of management continue to apply, with emphasis on sleep routines and identifying contributors to sleep disturbance to minimise disruption from treatable causes.
}

taking precedence; sleep issues must therefore be directly enquired about in order for resolution to occur.

\section{BEING ALERT TO CERTAIN CONDITIONS AND THOSE FEATURES RAISING CONCERN FOR POSSIBLE ALTERNATIVE DIAGNOSES}

While much of the time we can be reassuring about sleep patterns and how they may change (and hopefully improve) over time with appropriate advice, there are certain conditions and concerning features (tables 1 and 2) that should be recognised and considered, including the need for further investigation and intervention where appropriate.

\section{TRICKY QUESTIONS}

\section{Is it $\mathrm{OK}$ to let my child cry themselves to sleep?}

Controlled-crying or sleep-training are widely used, and useful, techniques. In a recent review, 49 of 52 (94\%) published studies of sleep behavioural interventions showed clinically significant improvements in settling and night waking problems in infants and children. ${ }^{8}$ The most extreme of such techniques is 'extinction'-leaving children to cry until they stop. 'Graduated extinction' involves attending to children at increasing time intervals and providing reassurance. 'Camping out' is where parents gradually remove themselves from the room.

Under the age of 6 months these interventions are not recommended, however for older infants these have been shown to be effective. ${ }^{9} 10$ They can be welcomed by parents exasperated by sleep deprivation due to the 'quick fix' they may provide. The other side of this debate is that infants left to cry can have increased cortisol levels suggesting activation of the stress-axis, and that close sleep-proximity (same room) to parents is associated with reduced infant-crying at night, therefore this may be a more favourable solution. ${ }^{11}$ However, for many families these remain useful techniques; a 5 -year follow-up study found no adverse effects on psychosocial functioning or relationships, concluding there were no significant longlasting effects of behavioural sleep interventions for infants. ${ }^{12}$

At later ages techniques to improve children's sleepconfidence are recommended. A balanced approach based on ensuring the infant/child feels secure, safe and confident in their sleep environment is usually appropriate.

\section{Is it OK to let my child sleep in my bed?}

Co-sleeping is common practice in many cultures, but is less common in Westernised societies, partly related to cultural expectations that children sleep in their own rooms/beds, and partly due to the association with sudden infant death syndrome.

A recent analysis of two case-control studies ${ }^{13}$ found factors associated with significantly raised risk of SIDS were: 


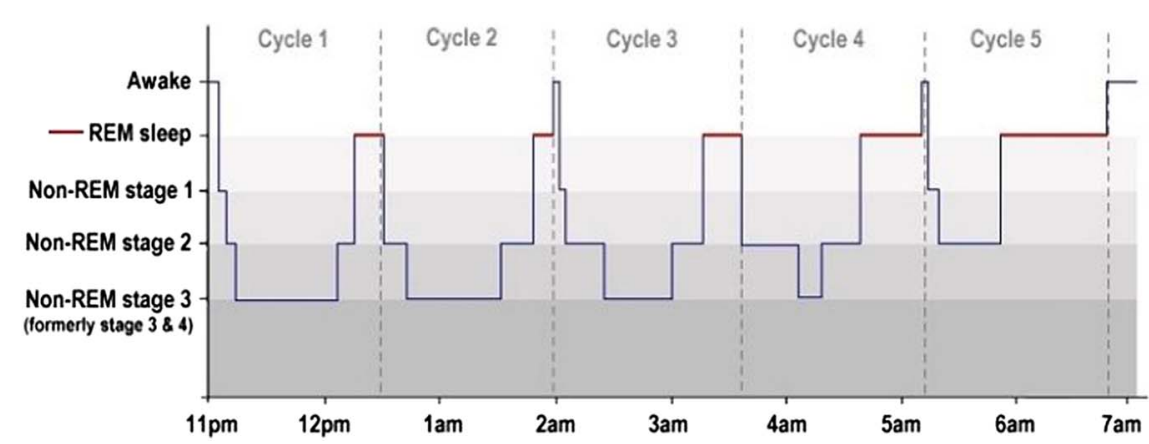

Figure 1 Typical hypnogram (adapted from Luke Mastin).

- co-sleeping with a parent who has consumed alcohol

- co-sleeping with a parent who smokes

- co-sleeping on the sofa.

There was a trend towards higher OR in premature infants and this was added as a risk factor. In the absence of these risk factors, the OR of SIDS for co-sleeping infants was not significantly raised, however this is not to say the risk for any individual infant is abolished; advice continues to be that the safest sleep position for infants $<6$ months is to be placed on their back, and in their own cot in the same room as their carers (National Institute for Health and Care Excellence (NICE) Clinical Guideline 37; Department of Health; NHS choices; Lullaby Trust). Guidance on co-sleeping differs between countries, and will change over time; recent evidence is brought together on the Infant Sleep Information Source (http://www.isisonline.org.uk), a useful resource to access.

\section{INTERVENTIONS}

The foundation of good quality sleep is the development of good sleep habits and routines (box 2). The same routine should be carried out nightly in order for 'cues' to sleep to become associated with sleep onset. Studies have found that consistent parental input, particularly around setting of bedtime rules is associated with longer average sleep durations. ${ }^{14}$

Some children require more input than others; children with higher levels of resistance to control were found to have more sleep problems and externalising behaviours than those more accepting of control. ${ }^{15}$ Parents in this circumstance may need a higher level of support in carrying through with setting a nighttime routine, and this should be anticipated from the outset to set expectations.

Physical exertion improves sleep quality; ${ }^{16}$ it has been found that just half an hour of high intensity physical exertion can be as effective as melatonin for

Table 1 Specific sleep conditions

\begin{tabular}{|c|c|}
\hline Specific sleep condition & Considerations \\
\hline $\begin{array}{l}\text { Partial arousal parasomnias } \\
\text { (confusional arousals, sleep terrors, sleepwalking): } \\
\text { Occurs between sleep states; accompanied by movement. Usually } \\
\text { occurs at predictable times earlier in the night (generally before } \\
\text { midnight). }\end{array}$ & $\begin{array}{l}\text { Ensure safety measures (eg, window and door locks) for sleepwalkers. Warn that } \\
\text { changes in the environment may confuse/be hazardous to children who may be able } \\
\text { to navigate their way around the 'known' environment. } \\
\text { Frightening for families, but does not generally cause harm. Reassurance and } \\
\text { explanation needed. }\end{array}$ \\
\hline $\begin{array}{l}\text { Obstructive sleep apnoea: } \\
\text { Snoring, gasping, pauses in breathing, daytime somnolence. Can } \\
\text { be a contributing factor to enuresis. }\end{array}$ & $\begin{array}{l}\text { Further assessment required which may include pulse oximetry, polysomnography } \\
\text { and/or referral to appropriate specialist (eg, ENT, respiratory paediatrician or sleep } \\
\text { service). }\end{array}$ \\
\hline $\begin{array}{l}\text { Restless legs syndrome: } \\
\text { Compelling feeling to move legs; associated with sensory } \\
\text { symptoms for example, skin crawling, itching (difficult for child to } \\
\text { describe). }\end{array}$ & $\begin{array}{l}\text { Can be associated with iron deficiency; consider trial of iron treatment if ferritin } \\
<50 \mu \mathrm{g} / \mathrm{L} \text {. } \\
\text { Often interpreted as 'growing pains'. }\end{array}$ \\
\hline $\begin{array}{l}\text { Nocturnal pain and night-time sweating: } \\
\text { Waking complaining of pain/ache. } \\
\text { Report of significant sweating in sleep. }\end{array}$ & $\begin{array}{l}\text { Common presentations, but potentially worrying therefore warrants evaluation. } \\
\text { Pain that is persistent, or not responsive to simple measures, may indicate pathological } \\
\text { pain such as dental pain or malignancy. } \\
\text { Sleep hyperhidrosis may occur as commonly as in } 11 \% \text { of children; }{ }^{22} \text { can be } \\
\text { associated with obstructive sleep apnoea, atopy and parasomnias. }\end{array}$ \\
\hline $\begin{array}{l}\text { Head-banging/body-rocking: } \\
\text { Usually a method of self-soothing (cf thumb-sucking); can be } \\
\text { associated with moaning. }\end{array}$ & Needs reassurance, generally does not result in injury. \\
\hline $\begin{array}{l}\text { Delayed sleep phase in adolescents: } \\
\text { Significantly delayed sleep onset. }\end{array}$ & $\begin{array}{l}\text { Some degree of circadian shift is physiological and normal in adolescence. Very } \\
\text { disordered sleep patterns (eg, staying awake all night and sleeping in the morning) } \\
\text { that are disruptive to everyday functioning warrant referral for specialist assessment. }\end{array}$ \\
\hline
\end{tabular}


Table 2 Red flags/concerning features

\begin{tabular}{ll}
\hline Sleep issue & Features raising concern \\
\hline $\begin{array}{l}\text { Multiple stereotyped night } \\
\text { wakings. }\end{array}$ & $\begin{array}{l}\text { Stereotyped movements. } \\
\text { Multiple episodes in the same night. } \\
\text { Predominant occurrence after first third of sleep period. } \\
\text { Event starts and stops suddenly. } \\
\text { While most unusual episodes during the night are parasomnias, the above features raise the level of concern for } \\
\text { possible nocturnal seizures; consider referral for specialist assessment. } \\
\text { Also lowered threshold for further assessment in children with atypical development or daytime seizures. }\end{array}$ \\
Nightmares with specific imagery. & $\begin{array}{l}\text { Persistent, severe, disruptive nightmares. } \\
\text { Nightmares consisting of concerning imagery-consider potential traumatic events in child's life. }\end{array}$ \\
Excessive/unusual daytime & $\begin{array}{l}\text { Consistent inability to stay awake during the daytime (including during activities child is engaged with) is very unusual } \\
\text { sleepiness. }\end{array}$ \\
beyond the age of normal daytime napping. \\
Consider-narcolepsy, obstructive sleep apnoea. \\
In sleep issue. & presenting sleep issue may be part of a wider neurodevelopmental dysfunction. \\
\hline
\end{tabular}

aiding sleep onset in children. ${ }^{17}$ Daily outdoor physical exertion is more difficult to achieve in today's society, but should be a goal for all children, and should be encouraged.

The child's wider sleep environment, including sleeping arrangements, bed comfort, temporary accommodation, shared living-sleeping spaces, are

\section{Box 2 Encouraging good sleep habits}

Physical exertion in the afternoon.

Consistent daily bedtime.

Last drink 1-1.5 hour(s) before bed (reduce chance of nocturia).

Avoid stimulating food and drink (eg, sugar/caffeine).

Wind-down time in the hour before attempting to settle to sleep (calming activities, eg, reading, board games, calming music).

No screens (television, phones, tablets) for at least 1 hour before bed.

No television in bedroom.

Low light during settling; red coloured light if night light is needed (does not interfere with natural melatonin production).

Having a transitional object (eg, a soft toy) to develop sleep confidence and a healthy sleep association.

Working towards child falling asleep by themselves in their own bed.

Limit setting on 'fussing' after 'lights out': 'I am going to give you one last kiss then it's time to sleep'.

Reducing attention given after 'lights out' to prevent reinforcing messages of attention (eg, avoid eye contact/ conversation). important as these may alter the recommendations given.

The stress hormone cortisol is antagonistic to melatonin, inhibiting sleep to maintain vigilance in times of perceived danger; ${ }^{2}$ enquiry about potential additional stressors including exposure to domestic violence, neglect or abuse, may be crucial in understanding the root cause of the sleep problem.

\section{MEDICATION}

The majority of children will respond to the behavioural management described, however a minority require specialist assessment and possibly medication. Melatonin is the most frequently prescribed of these. Other medications are available, however assessment by a specialist with an interest in sleep may be indicated if these are being considered. A useful review of medications for sleep disorders has been published previously. ${ }^{18}$

Melatonin is the natural sleep hormone produced by the pineal gland, and regulates sleep-wake cycles. Melatonin as a medication is currently unlicensed for use in children in the UK, however is prescribed with varying frequency by specialists and appears to be generally well tolerated.

Melatonin has specific uses. It can be effective in children in whom natural melatonin production may be disrupted, (eg, some children with ADHD, autism, visual impairment). ${ }^{2}$ It does not necessarily significantly increase total sleep duration, with an average increase of only $13 \mathrm{~min}$ in a study of children with neurodevelopmental disorders. ${ }^{19}$ In this study, although melatonin helped bring sleep onset forward by an average of $45 \mathrm{~min}$, it was also associated with earlier waking times in some children, thus not significantly increasing total sleep time for them. The main benefit of melatonin may be in helping children feel sleepier at sleep onset time, 
which in turn gives parents a better chance of making key changes to sleep routine and behaviour which, in the long term, are more likely to result in improved sleep quality.

The action of melatonin in inducing sleep occurs while levels are increasing within the bloodstream; once maximal levels are reached it loses efficacy. Baseline blood levels can increase with regular use; if efficacy is lost, stopping medication for 5 days (washout), and reintroducing at a lower dose may reinstate efficacy.

The sleep environment must also be conducive, with low lighting, calm atmosphere and absence of screens (blue wavelength light counteracts production of natural melatonin ${ }^{20}{ }^{21}$ ). It is important this is understood by parents; prescribing of melatonin should be part of an overall plan for good sleep habits, with appropriate timing of administration of melatonin (usually half an hour before the desired bedtime).

In children prescribed any medication for sleep, regular breaks in administration should be agreed to assess the need for ongoing prescription. Any prescription of medications unlicensed for use in children should be supported by a consultant paediatrician (eg, with shared-care agreement) in liaison with the general practitioner.

\section{STRUCTURED MANAGEMENT SUGGESTIONS}

- Look out for specific conditions and concerning features (tables 1 and 2).

- Minimise disruption from treatable causes such as asthma, nocturnal cough, eczema, gastro-oesophageal reflux.

- Explain the sleep cycle-parents are often not aware that night wakenings are part of the normal sleep cycle.

- Encourage good sleep habits (box 2).

- For child falling asleep late at night, gradually bring bedtime forward in small steps so the child continues to associate being in bed with falling asleep.

- Gradual removal of parent from room in a stepwise manner for a child who needs a parent present to fall asleep; sitting on bed, sitting by bed, facing away from bed, sitting away from bed, sitting in doorway, sitting outside bedroom, being away from bedroom (eg, 'making a cup of tea').

- Reinforce all achievements with praise and visual rewards such as star-chart; for star-charts to be successful they must be devised with the child, start with an achievable step ('I can fall asleep with Mummy sitting next to my bed'), be consistently applied, be made exciting and motivating for child (by changing reward when needed), and keep up momentum ('look, you've done brilliantly, now we can do the next step').

- Encourage and support parents in sticking with the routine; it takes a long time to break an undesirable sleep habit.
Resources

Contact a Family (http://www.cafamily.org.uk). Information leaflet 'Helping your child's sleep'. Developed for parents of disabled children, this has very relevant sleep information for all families.

- Royal College of Psychiatrists (http://www.rcpsych.ac. uk) factsheet 'Sleep problems in childhood and adolescence; for parents, carers and anyone who works with young people', covering a range of sleep problems in typically developing children.

- Lullaby Trust UK (http://www.lullabytrust.org.uk) It has a useful leaflet for parents on bed-sharing and safety.

- Raising Children Network (http://www.raisingchildren. net.au). It has sleep information and advice for different age groups, alongside other useful parenting tips.

- Kids Sleep Dr (http://www.kidssleepdr.com) app. Freely available through App Store; parents can enter data on child's sleep, export data by email and receive tips on successful sleep.

\section{Test your knowledge}

1. Waking during the night is a normal part of the sleep cycle. True or false?

2. On average children take 5 to 10 minutes to fall asleep. True or false?

3. Increasing the dose of melatonin would be the best option if the current dose has stopped working. True or false?

4. Head-banging during the night does not usually result in injury. True or false?

5. Restless sleepers do not need investigation. True or false?

Answers are at the end of the references.

Acknowledgements The authors thank Luke Mastin for permission to reproduce artwork of figure 1 .

Contributors JRT drafted the article and compiled tables/boxes. MF provided advice and editing.

Competing interests None declared.

Provenance and peer review Commissioned; externally peer reviewed.

\section{REFERENCES}

1 Blunden S, Lushington K, Lorenzen B. Are sleep problems under-recognised in general practice? Arch Dis Child 2004;89:708-12.

2 Gregory AM, Sadeh A. Sleep, emotional and behavioural difficulties in children and adolescents. Sleep Med Rev 2012;16:129-36. 
3 Stein MA, Mendelsohn J, Obermeyer WH, et al. Sleep and behavior problems in school-aged children. Pediatrics 2001;107:E60.

4 Taheri S. The link between short sleep duration and obesity: we should recommend more sleep to prevent obesity. Arch Dis Child 2006;91:881-4.

5 Vanable PA, Aikens JE, Tadimeti L, et al. Sleep latency and duration estimates among sleep disorder patients: variability as a function of sleep disorder diagnosis, sleep history, and psychological characteristics. Sleep 2000;23:71-9.

6 Blair PS, Humphreys JS, Gringras P, et al. Childhood sleep duration and associated demographic characteristics in an English Cohort. Sleep 2012;35:353-60.

7 Galland BC, Taylor BJ, Elder DE, et al. Normal sleep patterns in infants and children: a systematic review of observational studies. Sleep Med Rev 2012;16:213-22.

8 Mindell JA, Kuhn B, Lewin DS, et al. Behavioral treatment of bedtime problems and night wakings in infants and young children. Sleep 2006;29:1263-76.

9 Thunstrom M. A 2.5-year follow-up of infants treated for severe sleep problems. Ambul Child Health 2000;6:225-35.

10 Hiscock H, Wake M. Randomised controlled trial of behavioural infant sleep intervention to improve infant sleep and maternal mood. BMJ 2002;324:1062-7.

11 Blunden SL, Thompson KR, Dawson D. Behavioural sleep treatments and night time crying in infants: challenging the status quo. Sleep Med Rev 2011;15:327-34.

12 Price AM, Wake M, Ukoumunne OC, et al. Five-year follow-up of harms and benefits of behavioural infant sleep intervention: randomized trial. Pediatrics 2012;130:643-51.

13 Blair PS, Sidebotham P, Pease A, et al. Bed-sharing in the absence of hazardous circumstances: Is there a risk of Sudden Infant Death Syndrome? An analysis from two case-control studies conducted in the UK. PLOS ONE 2014;9:e107799.

14 Adam EK, Snell EK, Pendry P. Sleep timing and quantity in ecological and family context: a nationally representative time-diary study. J Fam Psychol 2007;21:4-19.
15 Goodnight JA, Bates JE, Staples AD, et al. Temperamental resistance to control increases the association between sleep problems and externalizing behavior development. J Fam Psychol 2007;21:39-48.

16 Reid KJ, Baron KG, Lu B, et al. Aerobic exercise improves self-reported sleep and quality of life in older adults with insomnia. Sleep Med 2010;11:934-40.

17 Dworak M, Wiater A, Alfer D, et al. Increased slow wave sleep and reduced stage 2 sleep in children depending on exercise intensity. Sleep Med 2008;9:266-72.

18 Gringras P. When to use drugs to help sleep. Arch Dis Child 2008;93:976-81.

19 Gringras P, Gamble C, Jones AP, et al. Melatonin for sleep problems in children with neurodevelopmental disorders: a randomized double masked placebo controlled trial. BMJ 2012;345:e6664.

20 Takeuchi Y, Imamura S, Sawada Y, et al. Effects of different colors of light on melatonin suppression and expression analysis of AANAT1 and melanopsin in the eye of tropical damselfish. Gen Comp Endocrinol 2014;204:158-65.

21 Gringras P, Middleton B, Skene DJ, et al. Bigger, Brighter, Bluer-Better? Current light-emitting devices—adverse sleep properties and preventative strategies. Front Public Health 2015;3:233.

22 So HK, Li AM, Au CT, et al. Night sweats in children: prevalence and associated factors. Arch Dis Child 2012;97:470-3.

\section{Answers to the quiz}

1. True-see figure 1.

2. False -17 to 19 minutes is average.

3. False-stopping for 1 week and reintroducing may be more effective.

4. True.

5. False-restless legs syndrome can be associated with iron deficiency. 